\title{
PRIMER GENOMA MITOCONDRIAL EN RESTOS HUMANOS DE LA COSTA DE SANTA CRUZ, ARGENTINA
}

JOSEFINA M. B. MOTTIa, ERIKA HAGELBERG ${ }^{\text {b }}$, JOHN LINDO' RIPAN S. MALHI ${ }^{d}$ CLAUDIO M. BRAVI ${ }^{\mathrm{e}}$ \& RICARDO A. GUICHÓN ${ }^{\dagger}$

\begin{abstract}
RESUMEN
En este trabajo se presenta la secuencia completa de ADN mitocondrial, obtenida a partir de restos óseos de un hombre adulto, hallado en el sitio Cañadón Misioneros (provincia de Santa Cruz, Argentina), con una antigüedad de $70 \pm 30$ años antes del presente. La secuencia corresponde al haplogrupo (hg) D4h3a5, nativo de América y exclusivo del sur de Patagonia, donde ha sido descripto tanto en muestras antiguas como actuales. Esta secuencia constituye el primer dato de ADN mitocondrial en la costa atlántica de Patagonia con la resolución suficiente para definir a nivel de subhaplogrupo. Se discuten las implicancias en cuanto a los vínculos biológicos de las poblaciones que habitaron esa porción del espacio patagónico en el marco de la información genética y arqueológica disponible.
\end{abstract}

PALABRAS CLAVE: ADN mitocondrial, ADN antiguo, Nativos Americanos

\section{FIRST COMPLETE MITOCHONDRIAL GENOME SEQUENCE FROM HUMAN SKELETAL REMAINS OF THE COAST OF SANTA CRUZ, ARGENTINA}

\begin{abstract}
We describe the complete mitochondrial genome sequence of an adult male skeleton, discovered at Cañadón Misioneros (Santa Cruz Province, Argentina), and dated $70 \pm 30$ years before present. The DNA sequence corresponded to haplogroup D4h3a5, native to the Americas and exclusive to the south of Patagonia, where it has been observed both in ancient and present-day individuals. This is the first mitochondrial DNA data of the Atlantic coast of Patagonia of sufficient

a Laboratorio de Ecología Evolutiva Humana. NEIPHPA. Facultad de Ciencias Sociales. Universidad Nacional del Centro de la Provincia de Buenos Aires. Calle 508 N 881, 7631 Quequén, Argentina. josemotti@yahoo.com.ar

b Institute of Biosciences, University of Oslo, P.O. Box 1066, N-0316 Oslo, Norway. erika.hagelberg@ibv.uio.no

c Department of Anthropology, University of Illinois Urbana-Champaign, Urbana, IL 61801, USA. jlindo1@illinois.edu

d Department of Anthropology and Institute of Genomic Biology, University of Illinois Urbana-Champaign, Urbana, IL 61801, USA. malhi@illinois.edu

e Laboratorio de Genética Molecular Poblacional, IMBICE (CIC-PBA, CCT- CONICET), CC 403, 1900 La Plata, Argentina. cmbravi@yahoo.com.ar

f Laboratorio de Ecología Evolutiva Humana. NEIPHPA. Facultad de Ciencias Sociales. Universidad Nacional del Centro de la Provincia de Buenos Aires. Calle 508 N 881, 7631 Quequén, Argentina. guichon@infovia.com.ar
\end{abstract}


resolution to permit classification at the subhaplogroup level. The implications for the genetic affinities of populations of this region of Patagonia will be discussed in the context of available genetic and archaeological information.

KEY WORDS: mitochondrial DNA, ancient DNA, Native Americans

\section{INTRODUCCIÓN}

\section{Contexto arqueológico}

El paraje Cañadón Misioneros $(\mathrm{CM})$ se encuentra en la provincia argentina de Santa Cruz, ubicado sobre la margen sur del estuario del río Santa Cruz, al norte de la ciudad de Puerto Santa Cruz (Fig. 1). El lugar recibió su nombre debido a que en 1862 se instalaron allí los primeros misioneros anglicanos, que hicieron un intento evangelizador en la zona (Llaras Samitier, 1955; Martinic, 1997). La experiencia fracasó y el lugar quedó abandonado hasta 1872, cuando el mismo sitio fue elegido para el emplazamiento de una fábrica de harina y aceite de pescado. El emprendimiento sólo duró dos años y dejó como evidencia los restos de la fábrica y las viviendas de los trabajadores. Posteriormente, en 1878 fue fundado oficialmente el Puerto Santa Cruz. El interés por el sitio histórico, motivó la organización de tareas de excavación, durante las cuales se recuperó gran cantidad de objetos propios de fines del siglo XIX (Schávelzon et al. 2010). Los autores señalan como una característica notable del sitio, la alta presencia de artefactos líticos (lascas y núcleos), incluso en asociación con objetos históricos. Sin embargo, no ha sido posible determinar con exactitud en qué momento fueron utilizados. También hacen referencia a que todo el cañadón constituyó una buena fuente de aprovisionamiento de materia prima lítica.

Al norte del sitio donde se observan los restos de la ocupación histórica, al pie de una pequeña barranca, se detectó la presencia de un cuerpo humano que empezaba a aflorar por la acción de la erosión. El esqueleto fue recuperado por aficionados, quienes lo trasladaron al museo local "Carlos Borgialli". Años más tarde, los restos óseos fueron estudiados en dicho museo por Guichón y Suby. En el año 2004 Guichón retiró el canino superior izquierdo para la realización de estudios de ADN con autorización de la Dirección de Cultura de la Municipalidad de Puerto Santa Cruz. Los estudios realizados, indican que el esqueleto corresponde a un individuo adulto masculino de entre 35 y 45 años, con un fechado de 70 \pm 30 (UGAMS 3596). Este fechado ubica temporalmente al individuo a fines del siglo XIX, momento en que, como se señalara anteriormente, ocurría la instalación de los primeros asentamientos de colonos en la región. Es interesante señalar que la dieta inferida a partir del análisis de isótopos estables es de tipo terrestre y semejante a la de otros restos pre-contacto de la costa meridional de Santa Cruz y del estrecho de

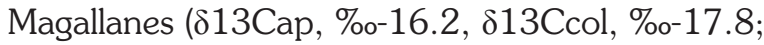
$\delta 15 \mathrm{~N}, \%$ \% 13.9; y C/N 3.06 (Suby et al. 2009). Se trata de un individuo con algunas características similares a las observadas en restos humanos asignados a indígenas de la región (morfología robusta y degaste dental plano con exposición de dentina secundaria).

En el año 2009 se creó el Reservorio Transitorio Co-gestionado de la municipalidad de Puerto Santa Cruz (Nahuelquir et al. 2014), donde actualmente se encuentran los restos; la ficha documental donde se registran los datos asociados al mismo, recibe el nombre de PSC0003.

La región donde fueron hallados los restos forma parte del territorio ocupado, en momentos de contacto, por grupos tehuelches, más precisamente aonikénk, como se llama a la parcialidad más sureña. Los aónikenk se caracterizaban por un modo de vida nómade que incluía el establecimiento de campamentos transitorios en la costa. Las fuentes etnográficas sugieren un uso invernal de la costa mientras que los datos arqueológicos plantean un uso no estacional de estos espacios en tiempos prehispánicos (Borrero, 1994-1995). Según quedó registrado en el diario del padre Schmidt, los indígenas tenían, hacia 1862, un campamento al norte del río Santa Cruz. También se registra el acercamiento de grupos indígenas a la costa con el objeto de intercambiar bienes con los tripulantes de barcos que llegaban a la zona (referencias del diario de Teophilus Schmidt, citado en Schávelzon et al. 2010). 


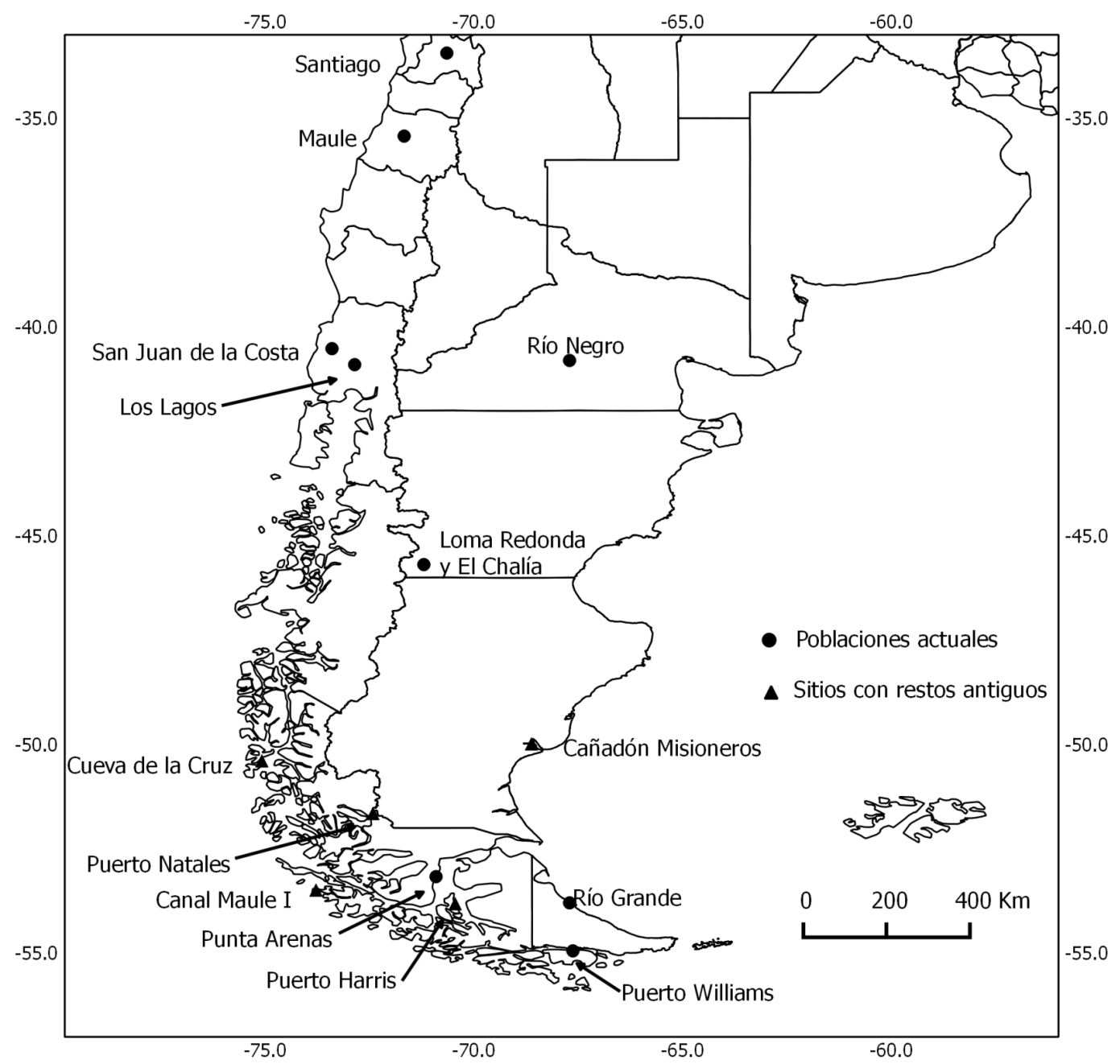

Fig. 1. Ubicación geográfica de las localidades mencionadas en el texto.

Antecedentes en estudios de ADN mitocondrial

En el marco de la teoría filogeográfica, el estudio de la variabilidad genética de las poblaciones permite dar cuenta de los procesos que han dado origen a los patrones de distribución actual de la misma (Avise, 2000). Este principio se ha aplicado en la reconstrucción de rutas de poblamiento que siguieron los seres humanos. El empleo de marcadores mitocondriales para caracterizar a las poblaciones nativas americanas, ha confirmado el origen asiático de éstas (Torroni et al. 1993) y ha sido utilizado para proponer modelos de poblamiento, que incluyen la sugerencia de la existencia de un tiempo de pausa en Beringia, durante el cual habría tenido lugar la fijación de las mutaciones que definen los linajes fundadores de América (Tamm et al. 2007).

El avance en las técnicas de análisis molecular que ha tenido lugar en los últimos años ha permitido superar la clásica distinción de cinco haplogrupos (hgs) nativos de América (A, B, C, D y X), identificándose actualmente por lo menos 13 subhaplogrupos que ya estaban diferenciados al momento de ingreso al continente americano (Tamm et al. 2007; Malhi et al. 2010; Perego et al. 2010; Kumar et al. 2011), algunos de los cuales presentan patrones de distribución que darían cuenta de distintas rutas de poblamiento, como el caso de D4h3a que se distribuye casi exclusivamente en el oeste del continente, desde Alaska hasta Tierra del 
Fuego y se asocia con un poblamiento por costa pacífica (Perego et al. 2009). Asimismo, al interior de cada subhaplogrupo se está avanzando en la definición de clados con distribuciones geográficas acotadas, que se habrían diferenciado localmente (Gayà-Vidal et al. 2011; Bodner et al. 2012; de Saint Pierre et al. 2012a,b; García et al. 2012; Motti, 2012; Taboada-Echalar et al. 2013).

En muestras antiguas de Patagonia se han obtenido datos de ADN mitocondrial con diferentes grados de resolución. Los análisis de polimorfismos en los fragmentos resultantes de la acción de enzimas de restricción (comúnmente conocido como análisis de RFLP, por sus siglas en inglés), señalaron la presencia exclusiva de los hgs $\mathrm{C}$ y D, datos que fueron interpretados inicialmente como prueba de que los habitantes de Tierra del Fuego serían los representantes de una primera migración carente de los hgs A y B (Lalueza-Fox et al. 1997). Posteriormente, el análisis de secuencias permitió aclarar que los linajes descriptos en Tierra del Fuego, son similares a aquellos propios del sur del continente y que por tanto no constituyen prueba alguna de una migración independiente (Moraga et al. 2000). Por otra parte, al hallazgo de 5 individuos con hg B en el sitio arqueológico de Baño Nuevo, en la Patagonia central chilena, con una antigüedad de entre 10.200 y 9.700 años calibrados antes del presente, da cuenta de que este hg habría estado presente entre los primeros ocupantes de la región, alcanzando latitudes más bajas que las registradas para la población actual (Reyes et al. 2012). En los trabajos donde se han obtenido secuencias de la Región Hiper Variable I (RHV I) ha sido posible identificar a los subhaplogrupos C1, D1g y D4h3a5, (García-Bour et al. 2004; Moraga et al. 2010). No han sido publicados hasta el momento secuencias mitocondriales completas en restos antiguos de Patagonia.

Las poblaciones nativas actuales de Patagonia se caracterizan por una disminución de la variabilidad a nivel de los linajes maternos: sólo cuatro subhaplogrupos de distribución continental restringida (B2i2, C1b13, D1g y D4h3a5) reúnen entre el 54 y el 93\% de los linajes presentes en poblaciones actuales. Independientemente de esta marcada reducción de la variabilidad pueden detectarse diferencias subregionales como la ausencia de B2i2 y la menor frecuencia de C1b13 en el extremo sur, que se asocian a un notable aumento de la frecuencia de D4h3a5 (de Saint Pierre et al. 2012a,b).

\section{Modelos de poblamiento propuestos para Patagonia}

En Patagonia se han hallado restos arqueológicos con una antigüedad que supera los 11.000 años (para una revisión de los fechados radiocarbónicos en Sudamérica, véase Steele \& Politis, 2009). Los hallazgos tempranos en América del Sur obligan a retrotraer la fecha de ingreso de los primeros americanos, contradiciendo el modelo de "Clovis, los primeros". Para poder explicar la presencia tan temprana en el extremo sur del continente, se ha propuesto una ruta costera de poblamiento, que habría recorrido la vertiente pacífica. Esta hipótesis se sustenta en la localización de los sitios más tempranos de Sudamérica y en modelos de desplazamiento humano que demuestran que los movimientos siguiendo la línea de costas son más rápidos que los intracontinentales (Dillehay et al. 2008).

En cuanto a la costa atlántica, el problema radica en que el ascenso del nivel del mar trasladó la línea de costa al interior del continente de modo que en caso de existir sitios costeros tempranos, éstos se hallarían bajo el mar. Sin embargo, teniendo en cuenta los sitios tempranos de la provincia de Buenos Aires y de la cuenca del río Deseado en Santa Cruz, se ha propuesto también que la costa atlántica habría sido de gran importancia durante el poblamiento inicial de Patagonia, ya que podrían haber constituido rutas litorales de desplazamiento. En ese sentido, se señala que los sitios tempranos cercanos al Atlántico se encuentran en los cursos medios de los ríos, sugiriendo un ingreso a través del litoral fluvial (Miotti \& Salemme, 2004; Miotti, 2006).

Desde el análisis de la morfología craneana, Guichón et al. (1989-1990) postularon la existencia de dos "stocks" biológicos, uno atlántico y otro pacífico, que habrian estado involucrados en el poblamiento de Tierra del Fuego. Posteriormente, González-José et al. (2004) ponen a prueba distintos modelos poblacionales para Patagonia y concluyen que el que mejor se ajusta a los datos es aquel que propone un ancestro común para los grupos fueguinos y patagónicos.

Como ya fue señalado anteriormente, los 
datos del ADN mitocondrial aportan evidencia en apoyo del modelo de poblamiento de América por la costa pacífica, atendiendo a la distribución actual del hg D4h3a. En Patagonia, este clado se encuentra a ambos lados de la cordillera, lo cual lleva a proponer que aquellos grupos humanos que vinieron siguiendo la ruta pacífica, se habrían visto impedidos de continuar más al sur, por la presencia de los hielos glaciares que se expandían más allá de los límites actuales hacia fines del pleistoceno. En este escenario, las poblaciones humanas habrian cruzado hacia el este, dado que luego del paralelo $39^{\circ}$, la altura de la cordillera de los Andes es menor (Saint Pierre et al. 2012a).

En cuanto a los subhaplogrupos recientemente descriptos, se ha propuesto que D1g ya habría estado presente en la población que venía avanzando y habría llegado hasta el centro de Chile, desde donde se habría expandido posteriormente; a juzgar por su antigüedad (18.300 años antes del presente según Bodner et al. 2012), su mayor expansión geográfica (que va desde Tierra del Fuego hasta el noroeste argentino), y su mayor variabilidad interna. Otros subhaplogrupos como B2i2 y C1b13, se estima que se habrian diferenciado posteriormente, una vez iniciado el proceso de tribalización (de Saint Pierre et al. 2012b); así se explica su menor rango de distribución geográfica y su menor tiempo estimado de coalescencia (10.800 y 12.000 años $\mathrm{AP}$, respectivamente).

De acuerdo con Borrero (2012), el tiempo y modo en que ocurrió el poblamiento humano en el extremo austral de América debe tener en cuenta por un lado la inestabilidad ambiental y climática ocurrida (especialmente durante la transición pleistocenoholoceno); y también el patrón de discontinuidades y vacíos que el registro arqueológico presenta para esta región. En este escenario del final del pleistoceno tanto la posibilidad de que muchas de estas primeras poblaciones no hayan sido viables; como también la capacidad de reacción de las poblaciones incluyendo migración y reorganización están siendo consideradas (Borrero, 2012). Es claro que ningún campo del conocimiento (genético, morfológíco, paleoecológico, arqueológico y bioarqueológico, por nombrar algunos) podrá abarcar la problemática del poblamiento humano por sí solo. Sin embargo, nuestro esquema de trabajo parte de considerar que los esfuerzos que se hagan por integrar información de distintas líneas de evidencia, permitirá ajustar los modelos, propiciando de esta manera una mejor aproximación a la complejidad del poblamiento en la región.

\section{MATERIALES Y MÉTODOS}

\section{Preparación de la muestra}

Los restos fueron procesados en la Unversidad de Oslo, Noruega, tal como fuera descripto previamente por Hagelberg y Clegg (1991). En este caso el canino superior izquierdo fue limpiado mediante abrasión con polvo de alúmina, y luego reducido a un polvo fino en un mortero refrigerado con nitrógeno líquido (Glen Creston, Stanmore, Inglaterra). Luego, el polvo de hueso fue almacenado a $-20^{\circ} \mathrm{C}$ en tubos estériles.

\section{Extracción de $A D N$ antiguo}

La extracción de ADN fue llevada a cabo en un laboratorio de ADN antiguo en la Universidad de Illinois Urbana-Champaign. Una descripción más extensa de las instalaciones puede leerse en la sección "Controles para evitar la contaminación".

Aproximadamente 0,2 gr de polvo de diente fueron incubados en $4 \mathrm{ml}$ de solución de desmineralización y lisis (0.5 M EDTA, pH 8, $33.3 \mathrm{mg} / \mathrm{ml}$ Proteinasa K, 10\% N-lauroilsarcosina) durante 24 horas a $37^{\circ} \mathrm{C}$. La muestra digerida fue luego concentrada en un volumen de $250 \mu \mathrm{l}$ mediante centrifugado con filtros Amicon. Luego de la concentración, la muestra fue procesada mediante columnas de sílica, usando el kit de purificación para PCR de Qiagen y luego eluída en un volumen final de $60 \mu \mathrm{l}$.

Preparación de la biblioteca genómica, enriquecimiento del ADN mitocondrial y secuenciación por Ilumina

Un volumen aproximado de $50 \mu \mathrm{l}$ del extracto de ADN fue usado para crear una biblioteca genómica con adaptadores que contienen un índice único para cada biblioteca. Se hicieron las siguientes modificaciones al protocolo de preparación de muestras TruSeq DNA V2; en primer lugar el extracto de ADN no fue cortado (sheared) ya que 
se espera que el ADN ya se encuentre fragmentado debido a procesos tafonómicos. En segundo lugar, se usó una dilución de los adaptadores de 1:20 debido a que se presumió una baja concentración de ADN en el extracto.

Se realizaron múltiples lavados Ampure Bead $X P$, para remover posibles dímeros de adaptadores. La amplificación mediante PCR de la biblioteca genómica fue preparada en el laboratorio de ADN antiguo $(25 \mu \mathrm{l}$ de reacción con $10 \mathrm{mM}$ de cebadores, 10x tampón de PCR, 10 mM Kappa DNTPs, KappaHiFi polimerasa y la biblioteca genómica) y luego transportada a termocicladores ubicados en el laboratorio de ADN actual, al otro lado del campus, en un ambiente sellado. La polimerasa $\mathrm{KapaHiFi}$ fue usada para amplificar las bibliotecas, debido a que esta enzima tiene una capacidad de corrección de pruebas, similar a otras polimerasas, que limita las incorporaciones erróneas de nucleótidos resultantes de la deaminación de la citosina (Fogg et al. 2002; Ginolhac et al. 2011). Las bibliotecas genómicas fueron amplificadas mediante 15 ciclos y fueron limpiadas con el kit de purificación Qiagen MinElute. La calidad de las bibliotecas fue evaluada en el Agilent 2100 Bioanalyzer, usando el High Sensitivity DNA kit. Las bibliotecas limpias fueron luego divididas en alícuotas de $5 \mu \mathrm{l}$ para amplificaciones adicionales hasta que la concentración final de todas las bibliotecas juntas, alcanzase los $100 \mathrm{ng} / \mu \mathrm{l}$. Un enriquecimiento dirigido del genoma mitocondrial fue luego llevado a cabo usando un kit de enriquecimiento dirigido personalizado MyBaits, siguiendo un protocolo de enriquecimiento modificado para $\mathrm{ADN}$ antiguo. Se realizó una amplificación final post-enriquecimiento de 15 ciclos. El producto de dicha amplificación fue cuantificado usando $\mathrm{qPCR}$ y luego remitido a la División de Secuenciación de Alto Rendimiento del Centro de Biotecnología W. M Keck en la Universidad de Illinois Urbana-Champaign.

\section{Análisis bioinformático}

Los datos crudos generados por la plataforma IluminaHiSeq2000, fueronanalizadosconCASAVA 1.8.2. Con el objeto de limitar la contaminación que pudiera ser introducida luego de la construcción de las bibliotecas, todas las lecturas que no exhibieron la secuencia exacta del índice fueron descartadas. Las secuencias de los adaptadores fueron cortadas usando AdapterRemoval (Lindgreen, 2012) con un largo mínimo de 25 pares de bases. Las secuencias fueron comparadas con la secuencia de referencia de Cambridge revisada (SRCr) mediante Bowtie2 2.1.0 (Langmead \& Salzberg, 2012) con una opción de realineamiento local y una semilla (seed) establecida en 1000. Las lecturas duplicadas fueron filtradas en base a las posiciones mapeadas (-rmdup-s) usando el paquete SAMtools 0.1.18 (Li et al. 2009). Los polimorfismos de nucleótido único (SNPs) y las inserciones y deleciones (INDELs) fueron identificadas usando el programa SNVer 0.4.1 (Wang et al. 2012). El umbral de calidad de los SNPs fue establecido para un modelo haploide, una profundidad de lectura de 20 , una base de calidad de 30 y una relación de alelo alternativo de 0.9.

Los daños en el ADN (tipo I y tipo II) fueron evaluados mediante comparación de las transiciones T-C/G-A y C-T/A-G, respectivamente, usando MapDamage 2.0 (Ginolhac et al. 2011). Un patrón específico de daño en el ADN antiguo fue identificado en trabajos anteriores (Briggs et al. 2007; Krause et al. 2010; Ginolhac et al. 2011). Estos estudios muestran un patrón de incremento del daño tipo II al principio y al final de los fragmentos de ADN degradado. Un patrón adicional puede ser inferido por un exceso de purinas antes de que comience la secuenciación, lo cual es indicativo de la fragmentación de las hebras causada por la depurinación post-mortem (Ginolhac et al. 2011). Nuestros resultados fueron comparados y se observaron los patrones de daño esperados para ADN antiguo.

\section{Controles para evitar la contaminación}

La extracción y amplificación del ADN fueron llevadas a cabo íntegramente en el laboratorio de ADN antiguo de la Universidad de Ilinois. Este laboratorio consiste en una sala con presión positiva y aire purificado con filtros HEPA. Posee además una antesala y el aire fluye desde la sala de ADN antiguo a la antesala y luego al pasillo. El personal que trabaja en el laboratorio de ADN antiguo usa material de protección descartable (gorros, máscaras, guantes, guardapolvos y botas). Todos los equipos, los reactivos y el material descartable son exclusivos para su uso en el laboratorio de $\mathrm{ADN}$ antiguo. El laboratorio de ADN antiguo es habitualmente lavado 
con hipoclorito de sodio y todos los recipientes son lavados con DNA-Away antes de ser usados en el laboratorio. El acceso del personal está restringido y no está permitido el acceso a personal desde el laboratorio de ADN actual. Se mantiene una base de datos con las secuencias de la Región Control del ADN mitocondrial de todo el personal. Se utilizan controles de contaminación en las reacciones de extracción y amplificación.

\section{Obtención de la secuencia actual}

En el marco del proyecto "Procesos de poblamiento en Tierra del Fuego. Una aproximación desde elestudio de los linajes maternos"; se obtuvieron muestras de saliva e información genealógica de miembros de la comunidad Selḱnam de la ciudad de Río Grande (Tierra del Fuego, Argentina). Las muestras fueron tomadas y almacenadas a campo con el kit Oragene•DISCOVER (OGR-250). Luego, se extrajo el ADN con un kit de columnas de sílica. El ADN extraído fue amplificado con los cebadores F15792 (5'-TCATTGGACAAGTAGCATCC-3', denominado 23F por Rieder et al. 1998) y R698 (5'-GCATGTGTAATCTTACTAAGAG-3'). Las condiciones de amplificación fueron las siguientes: 2 minutos de desnaturalización inicial a $94^{\circ} \mathrm{C}$ y 36 ciclos de desnaturalización a $94^{\circ} \mathrm{C}$ por 1 minuto, hibridación a $56^{\circ} \mathrm{C}$ por 1 minuto y extensión a $72^{\circ} \mathrm{C}$ durante 2 minutos, seguidos por una extensión final de 5 minutos. El éxito de la amplificación fue corroborado mediante electroforesis en gel de agarosa al $2 \%$. Los fragmentos amplificados fueron purificados y secuenciados por Macrogen Inc. La secuenciación se realizó en ambas direcciones, utilizando los mismos cebadores que para la amplificación e incluyendo además los cebadores F16475 (5'-TAGCTAAAGTGAACTGTATCC-3), Bailliet et al. (1994) y R285 (5-GTTATGATGTCT GTGTGGAA-3), Holland (2012). Las lecturas obtenidas fueron ensambladas y alineadas con respecto a la SRCr mediante el programa Sequencher 4.9 Demo, y se identificaron las diferencias con respecto a la SRCr. Se obtuvo así, la secuencia de la región control completa. Se presenta en este trabajo la única secuencia correspondiente a D4h3a, de un total de 7 individuos no emparentados por línea materna (correspondiente a la muestra SLK 02). Mediante la información genealógica se pudo constatar la ascendencia por línea materna de este donante a una mujer selḱnam que vivió a fines del siglo XIX.

\section{RESULTADOS}

Los polimorfismos encontrados en la secuencia mitocondrial completa de PSC0003 (Fig. 2), apoyan y modifican la redefinición del subhaplogrupo D4h3a5 propuesta por de Saint Pierre et al. (2012a). El clado D4h3a5 fue definido originalmente por Perego et al. (2009) en base a la presencia de una reversión en la posición 16301 -uno de los tres polimorfismos nodales de D4h3a en la RHV-I- en tres secuencias mitocondriales de Chile y una del norte peruano. Esta definición fue criticada como generadora de un grupo polifilético dado que la reversión en 16301 es recurrente, y se propuso que D4h3a5 sería un clado estrictamente patagónico definido por la co-ocurrencia de cuatro transiciones en región codificante $(9770,9821,12040,12528)$ y una en posición 16051 (de Saint Pierre et al. 2012a). La obtención de la secuencia completa de PSC0003 nos lleva a revisar esta definición, de la que debería excluirse 12040, ausente en la muestra antigua aquí informada. Del análisis de las secuencias completas (Fig. 2) y de las RHV-I (Fig. 3) resulta claro que la reversión al alelo SCRr en 16301 define un subclado mayoritario dentro de D4h3a5.

Se listan a continuación las mutaciones con respecto a la SRCr que definen al clado D4h3a.

SRCr - 263, 750, 1438, 4769, 8860, $15326-\mathrm{H}-73,2706,7028,11719,14766$ $-\mathrm{R}-12705,16223-\mathrm{N}-8701,9540,10398$, 10873, 15301 - L3 - 489, 10400, 14783, 15043 - M - 4883, 5178, 16362 - D - 3010, 8414, 14668 - D4 - 3336, 3644, 5048 - D4h - 152, 13135, 16301, 16342 - D4h3 - 3396, 4025, 6285, 8946, 9458, 16241 - D4h3a.

Hasta el momento se han publicado 22 secuencias parciales y 4 secuencias completas asignables a D4h3a5, todas ellas provenientes del sur de Argentina y Chile. Se incluyen dentro de este clado 5 secuencias de ADN antiguo, cuyo rango de lectura no alcanza la posición 16051, pero se asume que corresponden a D4h3a5 en base a la presencia de la reversión en 16301. De todas las secuencias publicadas, sólo 6 carecen de la reversión en la posición 16301 (polimorfismo 


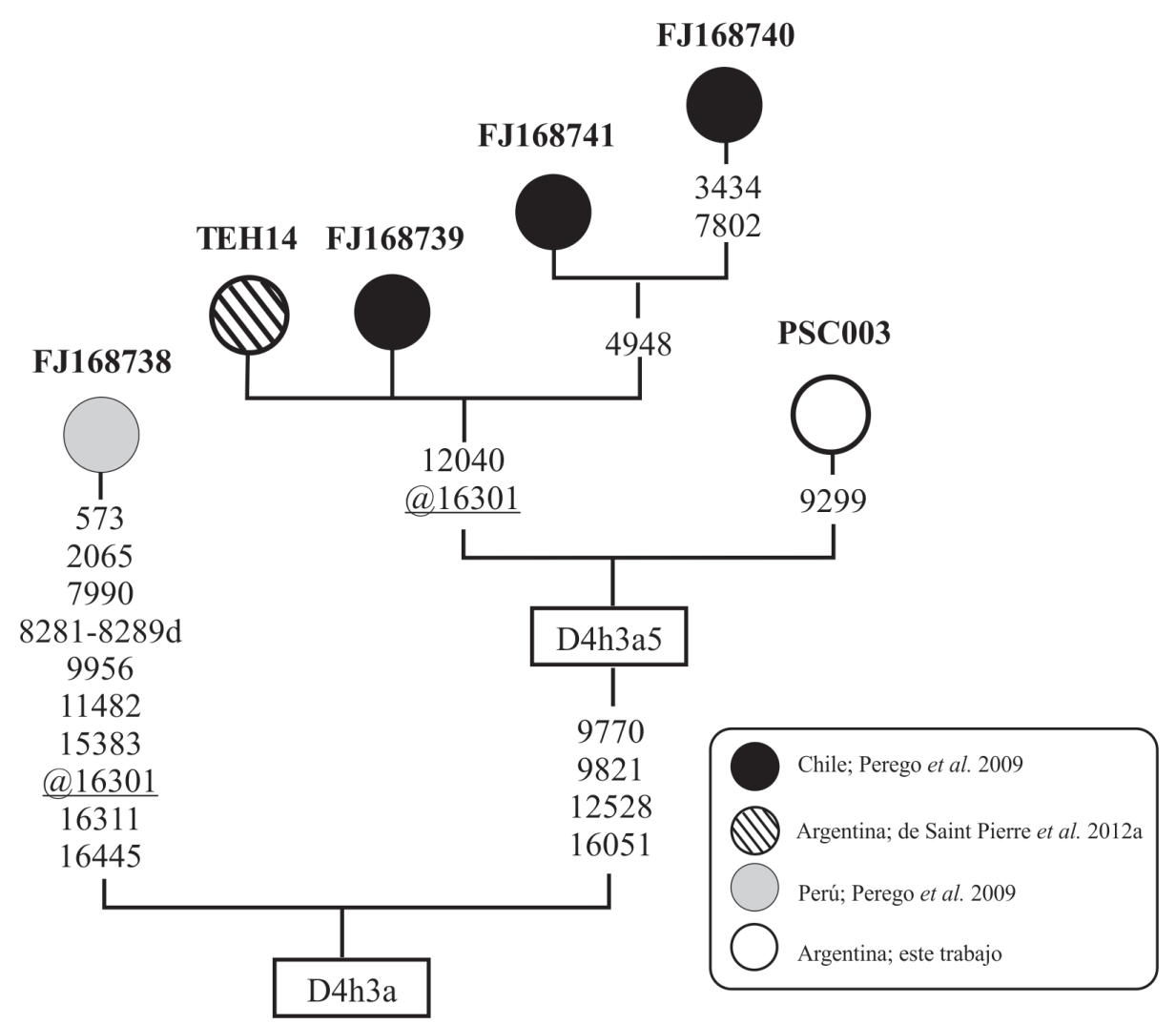

Fig. 2. Filogenia de D4h3a5, basada en secuencias completas.

C16301T), las cuales corresponden a individuos auto-identificados como tehuelches. En este trabajo se presentan dos nuevas secuencias pertenecientes a D4h3a5: la ya mencionada PSC003, que posee el polimorfismo ancestral C16301T y una secuencia perteneciente a un miembro actual de la comunidad selk'nam (Río Grande, Argentina), que posee el polimorfismo derivado T16301C. La variabilidad dentro del clado puede observarse en la tabla 1 y Fig. 3. En la Fig. 3 se incluyen las reversiones inferidas en 16241 y 16362 correspondientes a tres muestras antiguas de García-Bour et al. (2004). Vale la pena recordar que la integridad de algunas de las secuencias publicadas en ese trabajo ha sido correctamente criticada por Bandelt (2005), por lo que la ausencia putativa de 16241 y 16362, polimorfismos nodales de D4h3a, deben ser consideradas con precaución.

La presencia de este clado está restringida al sur de Argentina y Chile. A diferencia de otros clados patagónicos como D1g o C1b13, con representación tanto en el norte como en el sur de Patagonia, D4h3a5 aparece con mayor frecuencia en el sur de Patagonia, el hallazgo de este linaje en menores latitudes como la región de Los Lagos, Maule y Santiago en Chile y Río Negro en Argentina, puede ser explicada por los cambios ocurridos en tiempos históricos, incluyendo migraciones recientes hacia los centros de atracción económica. Emperaire en su clásica obra "Los nómades del mar", relata cómo las mujeres kaweskar solían embarcarse junto a loberos provenientes de Chiloé, y partían rumbo al norte (Emperaire, 2002). Es interesante destacar la alta representación que este clado tiene entre los kaweskar (46\%) y entre los tehuelches (27\%), mientras que entre los yámanas desciende al $9 \%$ y entre los huiliches sólo representa el 2\% (de Saint Pierre et al. 2012a). También es notable la restricción del polimorfismo C16301T dentro de D4h3a5, descripto hasta el momento sólo en a grupos tehuelches y en PSC0003, mientras que el resto de los casos reportados, presentan la mutación derivada T16301C (Fig. 3). 


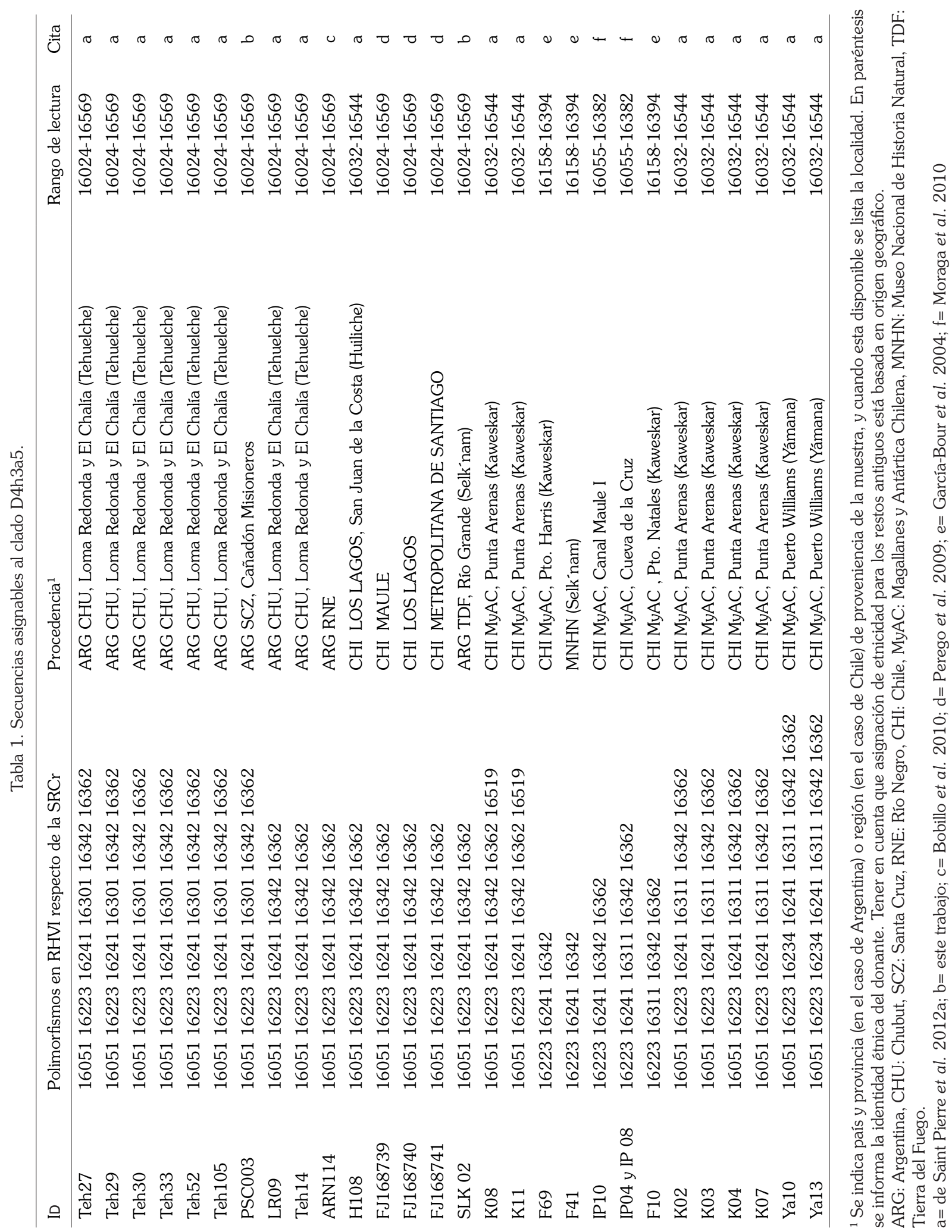




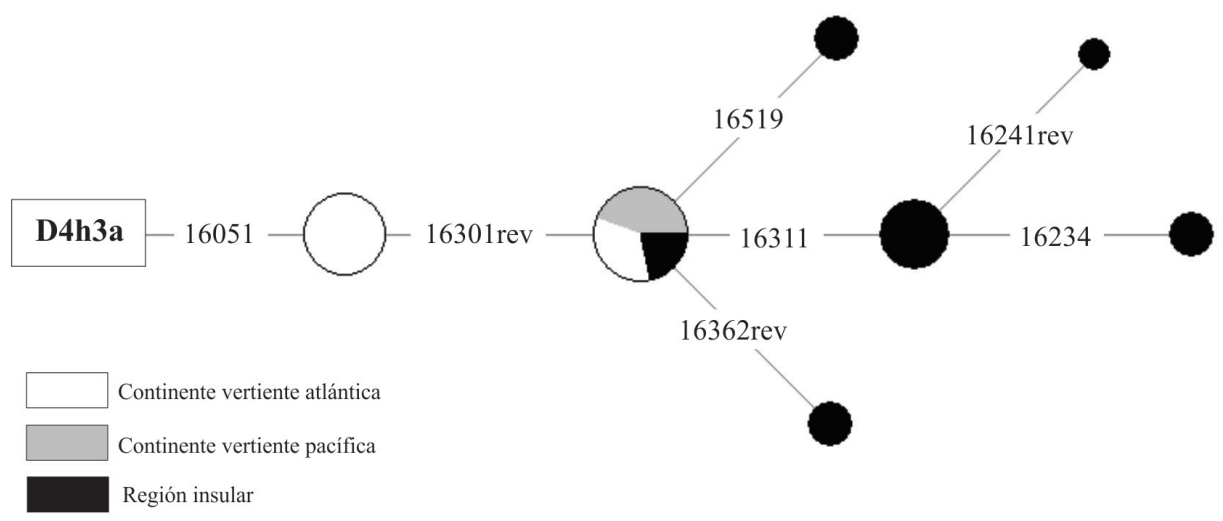

Fig. 3. Red de haplotipos correspondientes a D4h3a5. Mutaciones en RHVI que definen a D4h3a: 16223, 16241, 16301, 16342, 16362. Se supone la presencia de 16051 en aquellos haplotipos donde el rango de lectura no alcanzó esa posición. La región insular incluye a Punta Arenas y Puerto Natales.

\section{DISCUSIÓN Y CONCLUSIONES}

El individuo cuyos restos se hallaron en $\mathrm{CM}$, posee un linaje mitocondrial nativo americano y más precisamente un subhaplogrupo propio del sur de Patagonia. Éste, denominado D4h3a5, ha sido descripto anteriormente en localidades ubicadas en el interior continental o en la vertiente pacífica (ver Tabla 1 y Fig. 1). La presencia de este linaje también en la costa atlántica patagónica es coherente con la información etnográfica que da cuenta de la movilidad de los grupos habitantes de esta región (Martinic, 1995), así como también con los datos arqueológicos referidos a la presencia en la costa de materias primas provenientes del interior (Caracotche et al. 2005; Cruz et al. 2010), y con los datos bioarqueológicos que señalan una dieta del tipo terrestre en la costa de Santa Cruz (Suby et al. 2009).

Recientemente fue publicada la secuencia mitocondrial completa de un niño Clovis, proveniente del oeste de Montana en Estados Unidos de América, la cual corresponde al haplotipo nodal para el hg D4h3a (Rasmussen et al. 2014). El subhaplogrupo descripto en Patagonia Austral, D4h3a5, deriva directamente de la secuencia nodal y difiere de la misma por cuatro pasos mutacionales. El hecho de que derive directamente de la secuencia nodal y no de otro subhaplogrupo situado en la ruta intermedia entre América del norte y el extremo austral, da cuenta de la rápida expansión de los grupos humanos durante el poblamiento de América, ya que esto implica que no hubo un tiempo de pausa, donde tuviera lugar la fijación de mutaciones. Al respecto creemos pertinente aclarar a qué nos referimos con el término "rápida", ya que es un término ambiguo que puede llevar a distintas interpretaciones; en términos moleculares la tasa de mutación, aún la más veloz propuesta en base a estudios filogenéticos (Howell et al. 2003), requiere en promedio de casi 2.000 años para la adición de un paso mutacional, por tanto "rápido" en términos de la historia evolutiva de los linajes moleculares, puede diferir significativamente de dicho concepto en términos de la historia humana.

Retomando el trabajo de de Saint Pierre et al. (2012a), la evidencia mitocondrial con la que contamos actualmente para Patagonia señala, por un lado, que las poblaciones que poblaron este territorio venían siguiendo la ruta pacífica $y$, por otro que existe una continuidad entre los primeros pobladores y los grupos aborígenes actuales. En este contexto, podemos asumir que lo señalado por Borrero (1994-1995) respecto de la posibilidad de que en el poblamiento del espacio patagónico, tuvieran lugar fenómenos de extinción y reemplazo poblacional, podría ser entendido como fenómenos de extinción locales y que los espacios vacantes habrían sido repoblados por otros grupos de regiones aledañas, muy próximos genéticamente a sus predecesores. De ser así, no sería posible identificar mediante el análisis del ADN mitocondrial, la extinción de metapoblaciones. El grado de resolución que ofrecen dichos estudios, sí permite por el momento descartar la llegada de nuevas poblaciones colonizadoras provenientes del ambiente extra-patagónico. Así es posible reconciliar el modelo propuesto desde la arqueología que se centra en una microescala regional, con el modelo 
propuesto desde la genética, que hace foco en escalas geográficas más amplias.

En el caso de D4h3a5, su antigüedad estimada es menor a la de los otros subhaplogrupos patagónicos, 9.900 años AP (de Saint Pierre et al. 2012a) y su restricción al sur de Patagonia-Tierra del Fuego permite proponer un origen aún posterior, en el seno de la población que atravesó los Andes y se instaló en la vertiente atlántica de la Patagonia. Este modelo se apoya también en la distribución del haplotipo ancestral (sin la reversión 16301), descripto en PSC0003 y en tehuelches actuales. De esta manera, se propone como hipótesis que la diferenciación de D4h3a5 habría tenido lugar en la vertiente atlántica de Patagonia Austral, desde donde se habría dispersado posteriormente hacia Tierra del Fuego y las regiones de Ultima Esperanza, Magallanes y Antártica chilena. Futuras investigaciones que permitan ampliar nuestro conocimiento sobre la variabilidad mitocondrial de Patagonia Austral, contribuirán a discutir, mejorar o reformular esta hipótesis.

\section{AGRADECIMIENTOS}

A las comunidades de Puerto Santa Cruz, Río Grande, Ushuaia y Tolhuin por su hospitalidad. A las autoridades de la Municipalidad de Puerto Santa Cruz y al entonces a cargo del Museo Sr. Mario Hernández. A Pamela García-Laborde, Marilina Martucci, Manuel D־ángelo y Carlos Huilinao, que participaron de la campaña durante la cual se obtuvo la muestra actual. A Marisol Schwab, Julieta Beltramo y Laura Jurado-Medina que colaboraron en el procesamiento de la muestra actual. A Patricia Palacio que confeccionó el mapa. A todos los miembros de los proyectos que se vienen desarrollando en Puerto Santa Cruz. Especialmente a la Dra. Isabel Cruz que ha aportado información documental importante para este trabajo y al Dr. Jorge A. Suby quien participó activamente durante varios años en los proyectos y generó información valiosa sobre los restos aquí presentados. RAG, CMB y JMBM son miembros de la carrera de investigador del CONICET. Financiación: PICT $2008 \mathrm{~N}^{\circ} 0715$, PIP 2010-2012 N²0090100001, PICT 2010 $\mathrm{N}^{\circ}$ 0575, UNPA 29/A302 y PIP 2013-2015 $\mathrm{N}^{\circ}$ 11220120100359 CO.

\section{BIBLIOGRAFÍA}

Avise, J. C. (2000). Phylogeography: the history and formation of species. Londres: Harvard University Press.

Bailliet, G., Rothhammer, F., Carnese, F. R., Bravi, C. M., \& Bianchi, N. O. (1994). Founder mitochondrial haplotypes in Amerindian populations. American Journal of Human Genetics, 55(1), 27-33.

Bandelt, H-J. (2005). Mosaics of ancient mitochondrial DNA : positive indicators of nonauthenticity. European Journal of Human Genetics, 13, 1106-1112.

Briggs, A. W., Stenzel, U., Johnson, P. L., Green, R. E., Kelso, J., Prüfer, K.,..Pääbo, S. (2007). Patterns of damage in genomic DNA sequences from a Neandertal. Proceedings of the National Academy of Sciences, 104(37), 14616-14621.

Bobillo, M. C., Zimmermann, B., Sala, A., Huber, G., Röck, A., Bandelt, J....Parson, W. (2010). Amerindian mitochondrial DNA haplogroups predominate in the population of Argentina: towards a first nationwide forensic mitochondrial DNA sequence database. International Journal of Legal Medicine, 124(4), 263-268.

Bodner, M., Perego, U. A., Huber, G., Fendt, L., Röck, A. W., Zimmermann, B., ...Parson, W. (2012). Rapid coastal spread of First Americans: Novel insights from South America's Southern Cone mitochondrial genomes. Genome Research, 22(5), 811-820.

Borrero, L. A. (1994-1995). Arqueología de la Patagonia. Palimpsesto. Revista de Arqueología, 4, 9-69.

Borrero, L. A. (2012). The human colonization of the high Andes and Southern South America during the cold pulses of the late Pleistocene. En M. I. Eren (Ed.), Hunter-Gatherer Behavior: Human Response during The Younger Dryas. (pp. 57-78). San Francisco: Left Coast Press.

Caracotche, M. S., Cruz, I., Espinosa, S., Carballo, F., \& Belardi, J. B. (2005). Rescate arqueológico en el Parque Nacional Monte León (Santa Cruz, Argentina). Magallania, 33 (2), 143-163.

Cruz, I., Muñoz, A. S., \& Lobbia, P. A. (2010). Zooarqueología al sur del río Santa Cruz (Patagonia Argentina). Los restos de fauna del P96 (Punta entrada) y CL 1 (P. N. Monte León). En J. R. Bárcena, \& H. Chiavazza (Eds.), Arqueología Argentina en el Bicentenario de la Revolución de Mayo Tomo 1 (pp. 315-320). Mendoza: Facultad de Filosofía y Letras, UNCu e Instituto de Ciencias Humanas Sociales y Ambientales, Conicet. 
De Saint Pierre, M., Bravi, C. M., Motti, J. M. B., Fuku, N., Tanaka, M., Llop, E.,... \& Moraga, M. (2012a). An alternative model for the early peopling of southern South America revealed by analyses of three new mitochondrial DNA haplogroups. PloS one, 7(9), e43486. doi: 10.1371/journal.pone.0043486

De Saint Pierre M., Gandini, F., Perego, U. A., Bodner, M., Gómez-Carballa, A., Corach, D.,... Olivieri, A. (2012b). Arrival of paleo-indians to the southern cone of South America: new clues from mitogenomes. PloS one, 7(12), e51311. doi: 10.1371/journal.pone.0051311

Dillehay, T. D., Ramírez, C., Pino, M., Collins, M. B., Rossen, J., \& Pino-Navarro, J. D. (2008). Monte Verde: seaweed, food, medicine, and the peopling of South America. Science, 320(5877), 784-786.

Emperaire, J. (2002). Los nómades del mar. Santiago de Chile: Lom Ediciones.

Fogg, M. J., Pearl, L. H., \& Connolly, B. A. (2002). Structural basis for uracil recognition by archaeal family B DNA polymerases. Nature Structural \& Molecular Biology, 9(12), 922-927.

García, A., Pauro, M., Nores, R., Bravi, C. M., \& Demarchi, D. A. (2012). Phylogeography of mitochondrial haplogroup D1: An early spread of subhaplogroup D1j from Central Argentina. American Journal of Physical Anthropology, 149(4), 583-590.

García-Bour, J., Pérez-Pérez, A., Alvarez, S., Fernandez, E., Lopez-Parra, A. M., Arroyo-Pardo, E., \& Turbon, D. (2004). Early population differentiation in extinct aborigines from Tierra del Fuego-Patagonia: Ancient mtDNA sequences and Y-chromosome STR characterization. American Journal of Physical Anthropology, 370, 361-370.

Gayà-Vidal, M., Moral, P., Saenz-Ruales, N., Gerbault, P., Tonasso, L., Villena, M.,...Dugoujon, J-M. (2011). mtDNA and Y-chromosome diversity in Aymaras and Quechuas from Bolivia: Different stories and special genetic traits of the Andean Altiplano populations. American Journal of Physical Anthropology, 145(2), 215-230.

Ginolhac, A., Rasmussen, M., Gilbert, M. T. P., Willerslev, E., \& Orlando, L. (2011). mapDamage: testing for damage patterns in ancient DNA sequences. Bioinformatics, 27(15), 2153-2155.

González-José, R., Martínez-Abadías, N., Van Der Molen, S., García-Moro, C., Dahinten, S., \& Hernández, M. (2004). Hipótesis acerca del poblamiento de Tierra del FuegoPatagonia a partir del análisis genético-poblacional de la variación craneofacial. Magallania, 32, 79-98.
Guichón, R. A., Marti, I., Aspillaga, E., Cocilovo, J. A., \& Rothhammer, F. (1989-1990). El poblamiento tardío de Tierra del Fuego. Runa, XIX, 27-39. Bs.As. Argentina.

Hagelberg, E., \& Clegg, J. B. (1991). Isolation and characterization of DNA from archaeological bone. Proceedings of the Royal Society of London, Series B, 244, 45-50.

Holland, M. M. (2012). Molecular analysis of the human mitochondrial DNA control region for forensic identity testing. Current Protocols in Human Genetics, 74, 14.7.1-14.7.23.

Howell, N., Smejkal, C. B., Mackey, D. A., Chinnery, P. F., Turnbull, D. M., \& Herrnstadt, C. (2003) The pedigree rate of sequence divergence in the human mitochondrial genome: there is a difference between phylogenetic and pedigree rates. American Journal of Human Genetics, 72(3), 659-670.

Krause, J., Briggs, A. W., Kircher, M., Maricic, T., Zwyns, N., Derevianko, A., \& Pääbo, S. (2010). A complete mtDNA genome of an early modern human from Kostenki, Russia. Current Biology, 20(3), 231-236.

Kumar, S., Bellis, C., Zlojutro, M., Melton, P. E., Blangero, J., \& Curran, J. E. (2011). Large scale mitochondrial sequencing in Mexican Americans suggests a reappraisal of Native American origins. BMC Evolutionary Biology, 11(1), 293.

Langmead, B., \& Salzberg, S. L. (2012). Fast gapped-read alignment with Bowtie 2. Nature Methods, 9(4), 357359.

Lalueza-Fox, C., Pérez-Pérez, A., Prats, E., Cornudella, L., \& Turbón D. (1997). Lack of founding Amerindian mitochondrial DNA lineages in extinct Aborigines from Tierra del Fuego - Patagonia. Human Molecular Genetics, 6(1), 41-46.

Li, H., Handsaker, B., Wysoker, A., Fennell, T., Ruan, J., Homer, N.,...Durbin, R. (2009). The sequence alignment/map format and SAMtools. Bioinformatics, 25(16), 2078-2079.

Lindgreen, S. (2012). Adapter Removal: easy cleaning of nextgeneration sequencing reads. BMC research notes, 5(1), 337.

Llaras Samitier, M. (1955) Historia de "Cañadón de los Misioneros". Argentina Austral, Año XVII N 290, 6-8.

Malhi, R. S., Cybulski, J. S., Tito, R. Y., Johnson, J., Harry, H., \& Dan, C. (2010). Brief communication : Mitochondrial haplotype $\mathrm{C} 4 \mathrm{c}$ confirmed as a founding genome in the Americas. American Journal of Physical Anthropology, 141, 494-497

Martinic, M. (1995). Los Aónikenk, historia y cultura. Punta 
Arenas: Ediciones Universidad de Magallanes.

Martinic, M. (1997). Las misiones cristianas entre los aónikenk

(1833-1910). Una historia de frustraciones. Anales del Instituto de la Patagonia, serie Ciencias Humanas (Vol. 25).

Miotti, L. (2006). La fachada atlántica, como puerta de ingreso alternativa de la colonización humana de América del Sur durante la transición Pleistoceno/Holoceno. En J. C. Jiménez López et al. (Eds.), $2^{\circ}$ Simposio Internacional del Hombre Temprano en América (pp. 155-188). México: Instituto Nacional de Antropología e Historia.

Miotti, L., \& Salemme, M. (2004). Poblamiento, movilidad y territorios entre las sociedades cazadoras-recolectoras de Patagonia. Complutum, 15, 177-206.

Moraga, M., Rocco, P., Miquel, J. F., Nervi, F., Llop, E., Chakraborty, R.,...Carvallo, P. (2000). Mitochondrial DNA polymorphisms in Chilean aboriginal populations: implications for the peopling of the southern cone of the continent. American Journal of Physical Anthropology, 113(1), 19-29.

Moraga, M., De Saint Pierre, M., Torres, F., \& Ríos, J. (2010). Vínculos de parentesco por vía materna entre los últimos descendientes de la etnia kawésqar y algunos entierros en los canales patagónicos: evidencia desde el estudio de linajes mitocondriales. Magallania, 38(2), 103-114.

Motti, J. M. B. (2012). Caracterización de linajes maternos en la población actual del Noroeste y Centro-oeste argentinos. (Tesis doctoral inédita). Facultad de Ciencias Naturales y Museo. Universidad Nacional de La Plata. La Plata, Argentina.

Nahuelquir, S., Huilinao, C., Huilinao, F., Guichón, R. A., Caracoche, S., \& García Laborde, P. (2014). Trabajamos juntos. Antes y después de la ordenanza municipal de Puerto Santa Cruz 169/9. En M. Fabra, M. Montenegro, \& M. E. Zabala (Eds.), La arqueología pública en Argentina: historias tendencias $y$ desafíos en la construcción de un campo disciplinar. Jujuy: Editorial de la Universidad Nacional de Jujuy (EDIUNJU). En prensa

Perego, U.A., Achilli, A., Angerhofer, N., Accetturo, M., Pala, M., Olivieri, A.,...Torroni, A. (2009). Distinctive PaleoIndian migration routes from Beringia marked by two rare mtDNA haplogroups. Current Biology, 19(1), $1-8$.

Perego, U.A., Angerhofer, N., Pala, M., Olivieri, A., Lancioni, H., Kashani, B. H.,...Torroni, A. (2010). The initial peopling of the Americas: A growing number of founding mitochondrial genomes from Beringia.
Genome Research, 20(9), 1174-1179.

Rasmussen, M., Anzick, S. L., Waters, M. R., Skoglund, P., Degiorgio, M., Stafford Jr, T. W.,...Willerslev, E. (2014). The genome of a late Pleistocene human from a Clovis burial site in western Montana. Nature, 506(7487), 225-229.

Reyes, O., Méndez Melgar, C., Mena, F., \& Moraga, M. (2012). The bioanthropological evidence of a ca. 10,000 CALYBP ten-individual group in central Patagonia. En L. Miotti, M. Salemme, N. Flegenheimer, \& T. Goebel (Eds.), Southbound: Late Pleistocene Peopling of Latin America (pp. 167-171). Texas: Center for the Study of the First Americans. Department of Anthropology. Texas A\&M University.

Rieder, M. J., Taylor, S. L., Tobe, V. O., \& Nickerson, D. A. (1998). Automating the identification of DNA variations using quality-based fluorescence re-sequencing: analysis of the human mitochondrial genome. Nucleic acids research, 26(4), 967-973.

Schávelzon, D., Carminati, M., \& Frazzi, P. (2010). El Cañadón Misioneros. Arqueología de asentamientos históricos temporales en la Patagonia. Cuba Arqueológica. Revista digital de Arqueología de Cuba y el Caribe, número monográfico 1, 1-51.

Steele, J., \& Politis, G. G. (2009). AMS 14C dating of early human occupation of southern South America. Journal of Archaeological Science, 36(2), 419-429.

Suby, J. A., Guichón, R. A., \& Zangrando, A. F. (2009). El registro biológico humano de la costa meridional de Santa Cruz. Revista Argentina de Antropología Biológica, 11(1), 109-124.

Taboada-Echalar, P., Álvarez-Iglesias, V., Heinz, T., VidalBralo, L., Gómez-Carballa, A., Catelli, L.,...Salas, A. (2013). The genetic legacy of the pre-colonial period in contemporary Bolivians. PloS one, 8(3), e58980. doi: 10.1371/journal.pone.0058980

Tamm, E., Kivisild, T., Reidla, M., Smith, D. G., Metspalu, M., Mulligan, C. J.,...Malhi, R. (2007). Beringian standstill and spread of Native American founders. PLoS One 2: e829. doi: 10.1371/journal.pone.0000829

Torroni, A., Schurr, T. G., Cabell, M. F., Brown, M. D., Neel, J. V., Larsen, M.,...Wallace, D. C. (1993). Asian affinities and continental radiation of the four founding Native American mtDNAs. American Journal of Human Genetics, 53(3), 563-590.

Wang, W., Hu, W., Hou, F., Hu, P., \& Wei, Z. (2012). SNVerGUI: a desktop tool for variant analysis of next-generation sequencing data. Journal of medical genetics, 49, 753-755 
